Football friends: adolescent boys' friendships inside an English professional football (soccer) academy

\author{
Adi Adams ${ }^{\mathrm{a} *}$ and Sam Carr ${ }^{\mathrm{b}}$ \\ ${ }^{a}$ Department of Sport and Physical Activity, Bournemouth University, Bournemouth, \\ $U K ;{ }^{b}$ Department of Education, University of Bath, Bath, UK \\ *Corresponding author. Email: aadams1@bournemouth.ac.uk
}




\title{
Football friends: adolescent boys' friendships inside an English professional football (soccer) academy
}

\author{
This qualitative research draws on data from semi-structured, in-depth interviews \\ to examine the friendships of twelve adolescent (14 and 15-year-old) boys within \\ a professional football club Academy: a setting marked by competition for places. \\ Findings highlight how boys fail to develop 'deep' friendships with other boys \\ inside the club; their peer-relationships, even when described as 'friendships,' are \\ devoid of trust and emotional intimacy. Instead, 'being mates' is experienced \\ within parameters of instrumentalism and individualism leading to superficial \\ and inauthentic friendships. There is some indication that boys developed closer \\ friendships with boys outside of the Academy, suggesting that competition is \\ implicated negatively in friendship-building and hinders the capabilities of these \\ boys to develop close friendships with teammates. Concluding this paper, we \\ acknowledge limitations of our data, discuss implications and challenges for \\ football academies, and highlight directions for future research.
}

Keywords: friendships, peer-relationships, boys, youth sport academies, football (soccer)

\section{Introduction}

This qualitative research explores the friendship experiences of a group of twelve adolescent boys (14 and 15 years old), offering an insight into the processes that mediate boys' friendships within the high-performance-driven, competitive 'workplace' ${ }^{1}$ of an English professional football club youth academy. ${ }^{2}$ Operating at the competitive end of the sport spectrum, the primary objective of an academy is to produce young players for the professional, adult team of a football club. ${ }^{3}$ Elite football academies, therefore, can be thought of as existing to 'develop players for the first team or (at least) generate income through the sale of 'marketable assets." ${ }^{, 4}$ Essentially, academies perform a production-line or conveyor-belt function. They are footballerfactories delivering young men into the adult work-force; that is, into the all-consuming 
work of professional football. ${ }^{5}$ Perhaps one of the most striking features of the professional football industry as a contemporary work-space is that there are few other employers that (can) recruit and train potential workers from such a young age as professional football clubs (although this is perhaps not surprising given boys' potential market value). If invited to do so, boys are only able to register (or 'sign') for one professional club Academy at a time (from their eighth birthday) and are contracted into such agreements because professional football clubs are keen to discover and secure talent at a young age.

Borrowing from ideas presented by Douglas Ezzy, ${ }^{6}$ we conceptualise football academies as contemporary (high-) performance-driven work-spaces, geared toward efficiency, productivity and competition. At West-Side Football Club Academy (a pseudonym for the site of the current study), boys are actively recruited (officially from eight years old but often courted from as young as five years old through networks of scouts and local development centres) and those who are signed to this Academy, participate in a training program in which they also travel to compete with other professional club academies. More broadly, during any given season in English football, there are approximately 10,000 boys aged between 8-16 years old in the youth development programs (academies) of the 92 English professional football clubs. ${ }^{7}$ Typically, academies consist of eight age group teams (Under-9 to Under-16) with just (approximately) 12-14 boys per age group. In recruitment or 'catchment' areas (90-mile radius) of thousands of eligible, talented and enthusiastic boys, Academy places are relatively limited and highly competitive.

For Ezzy, ${ }^{8}$ workplaces organised within parameters of competitiveness and high-performance can diminish social and communal workplace relations, stimulating a 'superficial trust' and simulacrum (performance, rather than authentic feeling) of 
community in the workplace 'family.' Workplaces geared toward competition, Ezzy ${ }^{9}$ argues, can result in the (re)production of an aggressive, strategic, narcissistic individualism, disturbing employees' commitment to genuine reciprocity within the workplace, while also leading to the (re)production of a 'minimal self.' Ezzy describes this minimalisation as a reduction in one's ability to participate in activities outside of the workplace, with people who cannot help one become a more productive worker: a demise of social relationships outside of the workplace. ${ }^{10}$

This current research paper, drawing on in-depth interview data, explores the lived-experiences of a group of 14 and 15-year-old boys $(n=12)$ registered to West-Side Football Club Academy. Guided by Ezzy's thinking around competitive workplace relations, ${ }^{11}$ we explore a complex understanding of what authentic friendships are, and argue that a competitive football (academy) experience can nurture individualism and superficial trust among adolescent boys, troubling both their peer-relationships inside as well as outside this work-space.

\section{Boys, friendship and sport}

Way, ${ }^{12}$ and others, have revealed that the peer-relationships, friendships and close friendships of children and young people are vital in establishing positive outcomes in emotional and physical well-being. ${ }^{13}$ Indeed, developmental literature has consistently identified youth friendship quality as a critical determinant of a variety of important variables such as overall satisfaction with peer interactions, contextual emotional health, peer acceptance and rejection, enhanced motivation, behavioural difficulties, and coping. ${ }^{14}$

Further, within sport, multiple researchers ${ }^{15}$ have recognised that youngsters' relationships with their peers in sport-related contexts have a significant role to play in shaping their broader mental health and wellbeing. For example, Carr's work ${ }^{16}$ from an 
attachment theory perspective has highlighted the importance (for mental wellbeing) of youngsters being able to develop sporting friendships and bonds characterised by a deep sense of emotional connection, care, and security (i.e., one's friends are viewed as a source of safety and emotional comfort during times of threat or emotional need). Carr ${ }^{17}$ has also discussed the potential implications that such close bonds (or lack of) within sport may have for how individuals go about building relationships with others outside of sport.

However, while friendships in sport have been identified as important in 'buffering' emotional threats and shaping well-being, competitive sport may in fact function as a significant impediment in the formation of peer relationships and friendships. Research by Zarbatany, Mcdougall, and Hymel, ${ }^{18}$ for example, suggests that boys' focus on status acquisition has a suppressive effect on their 'intimacy skills' leaving them feeling unable to disclose weakness which ultimately limits the emotional connections they make. In other work, Patrick, Ryan, Alfeld-Liro, Fredricks, Hruda, and Eccles, ${ }^{19}$ note that adolescents involved in 'non-school-based' talent contexts were more likely to see themselves as facing 'a choice' between their 'talent-based activity' and absorption in their school-based social relationships. Furthermore, Ommundsen, Roberts, Lemyre, and Miller, ${ }^{20}$ have suggested that being in conflict with a 'best friend' is a typical experience of young male soccer players. They identified that performanceoriented sport cultures seemed to inhibit positive friendship qualities by creating a competitive environment which encourages the perception that team mates are rivals and dampens the likelihood of intimacy and closeness. Where boys are involved in team sports, therefore, research suggests that (competitive) participation may be associated with lower levels of friendship intimacy. Such findings raise interesting issues related to 
the role of elite football academies and professional 'football culture' in the development of youth peer-friendships.

\section{The work-place culture of professional football}

While the game of football is often imbued with romantic cultural notions of 'making it' and the struggle to achieve what some might call every boy's dream, ${ }^{21}$ more critical scholars examining (adult) professional football culture have identified some of its cultural peculiarities. ${ }^{22}$ While focused on the adult levels rather than youth academies, ${ }^{1}$ this body of social research is helpful in developing an understanding of the industrial life-world the boys at West-Side (as potential industry employees) are on track to enter. Roderick, ${ }^{23}$ for example, has noted that the working lives of professional footballers are characterized most fundamentally by having to perform in teams to achieve success, yet with high levels of internal competition inevitable and with many players quite willing to 'shit on each other' (i.e., ruthlessly undermine teammates) to secure status within the team.

Akin to Ezzy's ${ }^{24}$ conceptualisation of the instrumental individualism of contemporary workplaces, where social relations are devoid of trust, authenticity and reciprocity, some research paints a vivid picture of how professional footballers learn early the competitive, uncaring, and uncertain nature of the (football) marketplace, of what it means to become a professional footballer and what it takes to sustain a career. ${ }^{25}$ Given these socio-cultural workplace conditions and the inherent competitiveness within football work-spaces to 'make it,' examinations of the cultural environment of youth academies may offer important insights into the processes by which adolescent

\footnotetext{
${ }^{1}$ There remains a paucity of research exploring the experiences of youth academy players below the age of 16-years-old.
} 
peer (work-place) relationships are negotiated in these early-career 'developmental' spaces.

Elsewhere, reflecting Ezzy's ${ }^{26}$ contention that workplaces geared towards competition and high-performance result in the (re)production of an aggressive, narcissistic individualism and disruption of social reciprocity among work colleagues, Kelly and Waddington have described the professional football industry as 'aggressive, tough, masculine, and at all times violent,' while Magee has written that football is a place where boys and men learn to 'look after themselves,' deploying physical aggression, verbal abuse and intimidation of others as part of the process. ${ }^{27}$ Furthermore, the intensity of competing professionally and socially with teammates in a culture described as 'replete with images of maleness" ${ }^{28}$ is further compounded by the pressures that coaches face to 'get results;' resulting in the deployment of authoritarian, abusive and (physically and symbolically) violent coaching and management methods. ${ }^{29}$ Demonstrating the persistence of this culture, Jones and Denison ${ }^{30}$ have hinted at the constant, competitive, 'disciplinary' nature of (now retired) professional footballers' relationships with former teammates and coaches in which they described experiencing day-to-day supervision and round-the-clock one-upmanship. Beyond romantic ideas of 'the beautiful game,' then, the available social research points to the social conditions and 'reality' of life in the professional game being marked by (hyper)masculinity, competition, individualism, constrained and constraining interpersonal relationships, and a generally uncaring environment.

However, while the football market (and work-)place is saturated with surplus labour and competition for places and an underlying emphasis on aggressive individualism, ${ }^{31}$ there is some evidence that, regardless of these disturbing workplace conditions, 'friendships do develop. ${ }^{32}$ Indeed, Roderick's ${ }^{33}$ research on the work of 
professional football identifies how professional footballers often rely on an informal network of friendships to negotiate feelings of insecurity resulting from the competitive dimensions of the football labour market and workplace.

While others have begun to explore the realm of elite football academies, for example, highlighting the rise of surveillance practices in these settings ${ }^{34}$ and the subsequent construction of a particular sense of self that reverts to 'silence' as a strategy for negotiating the institutional norms of the organisation, ${ }^{35}$ there remains a paucity of research examining the lived-experiences of boys at the (pre-16-year-old) Academylevels of professional football. In particular, current research has neglected to examine how peer-relationships and friendships play out in this kind of setting. In this paper, we are interested in Roderick's ${ }^{36}$ insight on friendships in professional football, and in interrogating whether friendships $d o$ develop (and what these look like) at the youth "academy" level of the game.

\section{Methodology}

\section{Context}

This research focuses on boys in the youth Academy of one professional football club, which we have given the name West-Side Football Club. For much of its recent history, West-Side Football Club has operated in the lower tiers of the English Football League pyramid. ${ }^{37}$ West-Side provides a structured training programme (Academy) for boys aged eight through to eighteen, with the goal of developing boys capable of entering into the professional game. At the age of eighteen, professional (salaried) contracts may be distributed to the young men the Club deem capable of contributing to the success of the 'first team' (the adult professional men's team competing in the Football League). In this respect, (youth) players can be viewed as (prospective) financial assets to the 
club, and will either help the team to achieve success on the field, or will be sold to other clubs for profit. Individuals who are perceived as not helpful in these aims will likely be 'released' from their contracts.

\section{Access and interviews}

Parker $^{38}$ has previously described professional football clubs as 'closed' social settings. With regards to accessing participants for this current study, West-Side was chosen for pragmatic reasons and convenience of access. Participants were 'previous acquaintances ${ }^{39}$ from the first author's time as an Academy coach at West-Side. Data for this study were generated utilising semi-structured in-depth interviews. All interviews were conducted by the first author: white, male, former semi-professional footballer and ex-West-Side Academy coach. Helping to mediate social desirability bias, at the time of interviews the first author was no longer a coach in this Academy: however, he did retain his affiliation as a nationally-licensed Football Association (F.A.) football coach: including up-to-date F.A. Safeguarding Children Certificate, and Disclosure and Barring Service (DBS) check. Recognising that interview participants for this research were under the legal age of consent, initial communications with parents by the first author included his F.A. coaches' association number (FAN) and a University/institution contact number allowing parents to follow up on claims made about the research and be reassured of the legitimacy of the project.

Interviews were conducted with twelve $(n=12) 14$-and-15-year-old boys, all White-British, registered to the club's Academy. The boys represented in this study were from one of the teams at West-Side, an Academy in which approximately 100 boys participate across eight age groups from eight to sixteen years old. The length of time boys had spent registered to West-Side's Academy varied between two and six years. None of these boys had been registered to other academies prior to joining the 
academy at West-Side: all of these boys had been identified, or 'scouted,' playing local football, therefore 'signing' for West-Side was their first venture into a professional football club academy environment. Interviews lasted between 60-120 minutes, and took place in a venue chosen by the participants (agreed with parents/guardians), with the majority being in their family homes. All participants agreed to the interviews being audio-recorded, with the understanding that their interview data would be anonymised when transcribed and that audio-recordings would be kept secure and destroyed upon completion of transcription.

During interviews, the semi-structured arrangement was useful for creating flexible, in-depth conversation. ${ }^{40}$ Early in an interview, for example, having the time and space to 'talk shop' about West-Side in an informal way, to share memories and stories of days-gone-by at West-Side, and to get the boys to give an account of their current football activity and 'average day' schedule was useful in (re-)establishing a sense of trust and rapport. In this respect, 'insiderness' and 'commonality' ${ }^{41}$ with the participants (i.e. shared history and similar biography) offered a mechanism through which the first author was brought 'closer' to the emotionality and insecurities of boys' everyday academy experience. However, we also recognise that commonality can orchestrate feelings of participants being 'special,' affecting reactions to stories as well as offering the basis for rapport and understanding. ${ }^{42}$ Moreover, there were key differences between interviewer and interviewee, and he was not one of them. Recognising, as Richardson ${ }^{43}$ has argued, that ' $[\mathrm{t}]$ here is no such thing as 'getting it right,' only 'getting it' differently contoured and nuanced' we acknowledge that questions posed in the interviews for this research may in some ways reflect the value stances of the first author: however, care has been taken to engage with and balance such 'good' and 'bad' orientations (or at least to bring the interviewer into view in the 
re-presentation of data, such that these orientations are made more visible, available, and able to be scrutinised).

\section{First author comment: on interviewing academy boys}

Conscious that connections to institutional power through one's professional background can impact adversely on the quality of interview data ${ }^{44}$ it was my intention before and during interviews to distance myself from West-Side academy. Given my previous role as a coach at West-Side, I felt it was important to stress to each boy interviewed that I no longer worked for nor had any influence at West-Side, whilst also clarifying what the interview data would and would not be used for. At one interview with a West-Side academy player, having distanced myself from West-Side and about to move into the 'nitty gritty' of semi-structured questions, I was told: 'You know me, Adi. I'll tell you what I think.' On the phone to the father of another academy player (following up on a request to interview his son), I was told: 'Yeah, he said he'll talk to you, he's got lots to say about West-Side.' During another interview, one boy told me:

\footnotetext{
"I feel like I can just say what I want and I know it'll help, whatever I say, like I know it'll help with your work, I can say what I think cos it's gonna help people, I can say how I really feel, and even if it's good or bad."
}

To me, this interview extract in particular offered some modest affirmation that my approach to interviewing was of value and was generating the open and rich interview data I was hoping for, although whether I have achieved an adequate understanding of the culture of West-Side and the experiences of this group of boys can be judged by the readers of this study. The above interview extract also offers tentative evidence that boys interviewed did not feel that they needed to give socially-desirable answers. Each of these moments strengthened my own confidence in the integrity and coherence of the 
data presented in this research and my confidence that boys were happy to talk to me openly and honestly about their experiences, encouraging a bold(er) interpretation of events and analysis of data generated.

\section{Analysing, interpreting and (re)presenting data}

Data for this research were generated somewhat organically through a wider research project focused on examining representations of masculinity among coaches and youth players within the football academy setting. In the current paper we focus on the emergent interview data generated around friendships in the context of the football Academy. In a flexible, yet systematic, process with similarities to grounded theory approaches, ${ }^{45}$ transcription and analysis of early in-depth interviews resulted in the piecing-together of fragments of interview data related to interpersonal relationships between players providing sociologically interesting themes. These fragments of data and themes began to inform subsequent interviews, resulting in the development of a set of coherent data speaking to friendships and peer-relationships at West-Side Academy.

Once data was being generated, the processes of analysing and interpreting this data were also set in motion. Similar to the data analysis and interpretation approach described by others, ${ }^{46}$ the first author found that the processes of data collection, analysis and interpretation were not distinct, linear tasks, but were intertwined throughout the data collection process. Interview transcriptions began as soon as possible upon completion of the interviews, often that evening, so that further interviews were conducted in light of the themes that had emerged from the previous interviews. ${ }^{47}$ Practically, the process of transcribing and writing up notes involved an empathic immersion in the data: ${ }^{48}$ including re-reading field notes or re-listening to interviews, to identify and connect individual 'units' of data scattered across interviews and observations. 
At this point, as Potrac and Jones have suggested, ${ }^{49}$ individual units of data could then be grouped, compared, merged, divided, and (re)constructed into 'themes' to allow more abstract levels of analysis to take place and more embracing thematic categories to be 'coded' and organised, whereby new concepts, themes, and categories could inductively 'arise' from the data. Like Sparkes and Smith, ${ }^{50}$ we experienced the process of analysing data as one requiring constant 'reflection on and interpretation of alternative explanations and interpretations.' Facilitating a discussion of 'alternative explanations' of the first author's initial interpretations, (anonymised) data and themes were shared with the second author, a 'critical friend' and research psychologist interested in adolescent peer-relationships, helping to 'guard against the filters' through which the first author interprets the world. ${ }^{51}$ Ultimately, this critical friendships resulted in something comparable to that which Cushion and Jones ${ }^{52}$ have described as the situating of (co-constructed) data 'themes' within (what we came to an agreement to be) a suitably theoretical and empirical framework: with data predominantly animated through Ezzy's ${ }^{53}$ discussion of work-place relations. In (re)presenting the data for the reader, we opted for a (perhaps crude) division of data, interpretations, and theoretical analysis: drawing on Guba and Lincoln, ${ }^{54}$ the logic behind such an assemblage of the data being not that data can 'speak for themselves,' but that the 'raw products' (data) and the 'processes used to compress them,' are more available and able 'to be inspected and confirmed by outside reviewers of the study.'

\section{Judging the quality of this research}

Finally, bringing this methodological discussion to a close, it is important to note that we do not claim our findings to be representative of, nor generalisable to, all boys in all youth academies in England. Indeed, in utilising a qualitative approach to data collection and analysis we do not aim to achieve traditionally quantitative judgement 
criteria such as objectivity, reliability, generalisability, and validity. ${ }^{55}$ Instead, we aim to provide readers - through our detailed descriptions of the methodological path the research took along with a richness of data and theoretically-informed analysis - with an 'audit trail, ${ }^{56}$ whereby readers can inspect our decision-making processes. Moreover, we aim for resonance ${ }^{57}$ and a sense of transferability or fittingness ${ }^{58}$ in which readers have an opportunity to vicariously experience the setting being explored, enabling them to contemplate what is happening in this particular setting (essentially a case study of one academy team) and whether, in their view, this might be applicable or transferable to other contexts. We are hopeful that the extensive qualitative data (re)presented - rare data in (youth) football studies - encourages and stimulates coaches, parents and academics alike to recognise these boys' experiences as meaningful, while developing our shared understanding of boys' peer-relationships and friendships in (competitive) football settings.

\section{Findings}

\section{Playing conditions at West-Side Academy}

In Roderick's paper on uncertainty in the lives of professional footballers, he outlines the social conditions of work in professional football. ${ }^{59}$ Building on Roderick's work, our findings evidence similar conditions of 'work' at play in West-Side Academy: performing work in teams, internal competition for places, and direct competition with teammates. As one Division Three player noted in Roderick's study: ${ }^{60}$ 'At the end of the day, you know, everyone is in it for themselves.' Similarly, we found that competition was deeply embedded in the fabric of boys' own experiences of the West-Side football Academy. As one West-Side Academy player, Alex, describes, it was important to constantly 'impress:' 
"You're trying to impress everyone, so if you know you're playing badly everyone will know that, so you want to impress everyone, your coach, the older age groups, your own age, and the year below." (Alex)

Echoing the climate of fear, direct competition and the fear of being replaced which saturated Roderick's own interviews with current and ex-professionals, the following interview extract with another West-Side Academy player, Jamie, adds further weight to the idea of competition and insecurity being interwoven into the West-Side Academy player experience:

\begin{abstract}
"When you think of it, it's scary, but it's something that makes you more determined cos you gotta like, you know, try and beat all the other people, you gotta be better than them. So it's worrying but it drives you a little bit." (Jamie)
\end{abstract}

Drawing on the two interview extracts above, we frame boys at West-Side as being embroiled in a hyper-competitive, high-performance-driven 'work-place' context. ${ }^{61}$ That is, being an Academy player in a professional football club like West-Side can mean being in a precarious, fragile and insecure situation, in similar ways to the experience of adult professional players described by Roderick. ${ }^{62}$

Data from interviews with two other Academy players at West-Side (Kyle and Toby) highlights how 'insecurity' and an individualistic personal focus is layered with(in) the lived-experience of the competitive social structure of West-Side Academy:

\footnotetext{
"They're always trying to look for someone better, always, like if there's someone better then they'll choose them over you. I think you're there cos they want you there, but only until they want someone else then they might not want you." (Kyle)

"You have to fight for your position, like, I wouldn't give up if someone come in and got signed on straight away, I'd be thinkin', I'd be lookin' at 'im thinkin' where am I better than 'im, where's he better than me, and I think, and if someone, if he's better than me in that position in that certain bit of technical ability, I'd just be like right I'm gonna focus on this, I need to get better." (Toby)
} 
A peculiarity in the lives of the Academy players, is that they are part of a team yet also in constant competition with their teammates. With this understanding of the texture and contours of Academy life, of the kinds of 'work' that is done by boys within academies, the following sections explore boys' friendships both inside and outside of the Academy.

\section{Navigating competition and friendships inside the Academy}

'Your mates back here [at home, away from the Academy] are your mates,' George notes in an interview, 'but you also call those lads at West-Side your mates too.' In this part of our analysis, we focus on the peer relationships and friendships (the depth of emotional-proximity) that Academy boys maintained 'inside' the Academy with their (team) mates. An avenue of exploration that provided a useful way of interpreting boys' friendships inside the Academy was through the comparisons they made with friendships outside of the Academy. Jack, for example, insightfully describes some of the complexities of his own peer-relationships with teammates at West-Side football Academy potentially being due to him being an 'out of town' player and sharing a different background and 'standards' to some of his teammates. For Jack, recently released by West-Side, this meant it was difficult to 'relate' to all of his teammates, particularly those who grew up in West-Side:

\footnotetext{
"Some, like [1], [2], and [3], you could talk to a lot more cos you could relate to them a bit more, whereas [4], [5], and [6], I still consider them my friends, but it was a bit more difficult to be yourself cos they sort of knew everything about each other and they sort of had their own standards of how they should be, and cos they come from West-Side, they sort of act hard and all that to sort of show everyone where they stand." ${ }^{63}$ (Jack)
}

Jack adds: 
"There was always a lot of banter, but, well, it was a bit more difficult for people like me and [1], cos there were like a group of boys who went to the same school who were from the same place who knew each other, and then there was me, [1], and [2]." (Jack)

Further, Jack recalls being called 'posh' by some of his teammates and how this 'banter' had 'dragged on' during his time at the Academy. While Jack initially plays these interactions down as not being 'that bad,' the following extract highlights themes of difference and class in his peer-relationship experiences as an Academy player at WestSide.

\begin{abstract}
“It wasn't that bad, I know he was only joking, but he really dragged on about it, especially me and [2], he'd put this really annoying voice on whenever we talked, cos he's got a proper West-Side accent, and I come from around people with [countryside] accents and all that, and I don't sound posher than anyone here at all, and I knew it was a joke, and it was funny sometimes, but he did it for so long, and it was sort of, it got really annoying. I think it did down my confidence a bit."
\end{abstract} (Jack)

Supporting the idea of competitiveness and hierarchy as being embedded into the peerrelationships of boys at West-Side Academy, George adds:

\footnotetext{
"There's something about football where everyone is trying to get the edge on each other, I've never known why, it's just maybe that even though you were in a team, it was competitive, playing for places. I thought it was a sort of way to put you down, sort of like just to get the edge, to knock your confidence, cos even though they were doing it in a jokey way you sort of knew what they were doing, it's sort of like a tactic to get people down and not play as well even though you're on the same team." (George)
}

Further, highlighting the complexity of the competitive yet collaborative institutional context these boys are in, Kyle comments: 'You just have to get on with it and try and be better than them but stay friends.' Kyle's response provides a flavour of how boys at 
West-Side perceived each other as threat to their own place at the Academy. Similarly, Joel tells us:

\begin{abstract}
"At the end of the season a new lad came in, he's a good player...and he was starting [in the team] in front of me, so that was a bit of a down for me...I thought I should be playing...coaches try and say 'don't worry'...but deep down you're thinking 'you shoulda put me on.' But you gotta smile and get your head down, I wanna try and improve and eventually I'll take his place....Things are different now to what they were a couple of years ago, it's a lot more serious now cos everyone's thinking 'Oh this could be a career,' and, um, 'I wanna make sure they [trialists] don't take my place,' but off the pitch I try and shake hands with them and say like, be welcoming and stuff, but on the pitch it's just...business." (Joel)
\end{abstract}

These interview excerpts hint at the competitive social conditions and context of lived experiences against which 'friendships' are developed and nurtured in this Academy setting: individuals are in competition with each other (ultimately for professional contracts) but simultaneously collaborate to achieve success 'in a team.' Kyle explains:

"When you're up the team [at West-Side] they [other Academy players] all wanna be pushed, but you don't wanna push each other too much in case they go ahead of you. Cos like you're in a team but you're individuals as well." (Kyle)

Other boys also discussed their friendships with other boys inside West-Side, comparing them with their 'other mates' from 'back at home.' As Alex highlights:

"Well, I don't compete against my other mates for everything like we do at WestSide...[with] mates at football it's always competition in everything you do, always wanna win, and everyone wants to be top dog." (Alex)

When asked what his school friends were like in comparison, Alex comments, 'I'd say they're more normal...cos they're not all like outgoing, like not always trying to outdo each other."” 
Against this backdrop of 'jokes,' 'banter,' and a culture of competition and playing for places, boys described their relationships with other boys in the Academy in ways that problematized their own self-described 'friendships.' For example, Jamie (who had been 'released' from the Academy six months before being interviewed) explains that other boys at West-Side were 'just people you go play football with.' Reflecting on some of his friendships during his time as a West-Side Academy player (he had 'signed' aged eight years old), Jamie notes that:

"You say they're your mates but actually since I've left none of them have bothered to get in touch, and I'm glad cos I've just forgot about West-Side. I left and it was gone, out of my head." (Jamie)

The following exchange on the same theme is also from the interview with Jamie:

Jamie: "Me and [1] and [2] used to be good mates, they used to come round or maybe we'd speak, but I never spoke to the others much outside of football anyway, you just call 'em your mates cos you know them and you play football with them, not like mates as in you can speak to them or you're really close to them, you just play footy together...it's not real friends, like me and [1] and [2], they could come round mine and we could speak about other people like 'Oh yeah I don't reckon he should be here' and we could speak about stuff like that before, but then I haven't spoke to them once since I've left, and I'm not that bothered so we can't have been that good of mates."

AA: "You don't think you were that good mates then?"

Jamie: "Yeah, well, they come, not last birthday but the one before, they come down, met my mates and we went paintballing and I've been up [1]'s house twice before and, yeah, but then since I've left I haven't been bothered about speaking to no one, I've been like, not even on the phone or BBM [instant messenger on mobile phone], some people I've deleted off Facebook [a social network website] cos I'm not ever gonna be friends with 'em. Still got [1] and [2], but most people, there's no point." 
Jamie's difficulties in being intimate or connecting emotionally with other boys from West-Side at a time of personal distress (being released), is itself distressing, particularly for the reason that the boys he is 'not bothered' about speaking to, or unable to connect with, are the very boys he describes as having been his primary friends over a number of years at West-Side. Noting how his football friendships (that is, on the inside of the Academy) were generally restrained (lacking trust, emotional proximity and authenticity) and how they have been disturbed and faded away since leaving the club, Jamie says:

"You talk about things, nothing secretly, just normal things, like how the match on the weekend, or what you done with your mates, stuff like this, you're just having fun and talking with your mates, nothing like oh come here let me tell you something, like I wouldn't have ever told anyone anything like at West-Side, like about secret stuff, I might've told [1], cos our dads are close as well, but I don't think I never even told him something, cos I've since the Under-9's knew him and I still talk to him normally now, just like oh who you playing this weekend and stuff like this and he asks me are you still on trial at [another professional football Academy] and he tries, he keeps in touch with me, like no one from West-Side has tried to keep in touch with me, so I haven't been bothered, but [1] tries, like so I try with him. I've popped up on BBM or Facechat with [2] and he's spoke to me but then like then he's never just popped up randomly, but then, like I said, I'm glad that I've just forgot about it." (Jamie)

Interestingly, being 'let go' seemed to have given Jamie a different perspective on his footballing friendships. As Jamie notes:

“Since I left, I don't think you realise when you are there, they were just actually people you played football with, they were just people, yeah you might've spoken to, but they were just people you play football with, enjoy yourself." (Jamie)

Adding weight to the idea of football friendships inside the Academy being about superficial 'jokey’ friendships but lacking trust and intimacy, Will (a current Academy 
player at the time of interview) talks about his friendship with his 'best mate' at WestSide, comparing this friendship with those outside the Academy: 'He makes an atmosphere,' Will explains, 'and I think that's why I get on with him, and people like him cos he livens it up.' On the social value of this friendship, he adds: 'If everyone's a bit quiet you can rely on him to say something stupid that'll get everyone laughing or he'll be the one that starts something off.' Probing further, the first author (AA) asks:

AA: "What's he like compared to your mates at home and at school?"

Will: “Um, little bit same, just he's got same sense of humour as me...we get along cos we have the right sense of humour and we take the mick all the time and we give each other banter."

AA: "Is he someone you feel like you are close to, like could you trust him with personal stuff, would you say?"

Will: 'No I couldn't, he's not one of them people I could go tell something, he's one of those I could go around with and if I went out with him I'd have a good laugh with him, um, which I couldn't with other people, but I wouldn't say that we was close like that."

Later in the same interview, Will describes in a similar fashion his friendship with a different (team)mate at West-Side Academy:

“He's a mate... but I wouldn't say too much to him cos I know he couldn't keep a secret, couldn't keep anything from anyone, the trust is not there...I wouldn't say he has got many real friends." (Will)

Will's discussion of 'real friends' is intriguing. Asked if he thinks he will stay in touch with any of the other boys over the next few years, as some progress to scholarships at West-Side and others are released, and the group becomes more fragmented, Will says: 
“There's a few I'll chat to, but I probably wouldn't go meet up with them because I'm not really close mates with anyone there, I'm mates but not to the extent that I'd go out and spend time and socialise with 'em, does that make sense?" (Will)

For the authors, Will's comments illuminate something that seemed peculiar to many boys' experiences of Academy friendships in that 'best friendships' seemed to involve (a) a lack of trust and intimacy, and (b) a questioning of the authenticity of the friendship as being 'not real.' Extracts from individual interviews with three other Academy players (Reece, Joel and Toby) further consolidated these interpretations and themes. Reece, for example, notes:

"You're closer with your mates from school cos you're with them longer...I'd rather talk to them about personal stuff than talk to people from football, cos people from football then might use that against you or something like that." (Reece)

Joel makes a similar distinction between his West-Side (team) mates and his school mates:

Joel: "They're all big characters, as individuals, all like that, it's just, but like other people back home aren't."

AA: "Ok, so if I asked you to put things in order, like, how close you are and how much you trust them, where would the West-Side lads be compared to other people in your life?"

Joel: "They'd be right at the back. Right at the bottom!"

AA: "What makes you say that?"

Joel: "Um, well, I dunno if that's how they would be, but I picture them as not being able to tell stuff to."

Similarly, explicating his own friendships with teammates at West-Side Academy as 
though they were of a different, superficial 'fabric' in relation to trust and levels of intimacy, Toby comments:

"I didn't speak to no one at West-Side outside of it, except for [1], but we never used to speak about stuff, like social stuff or anything deep, we just used to speak about football and like...that's all we really talked about." (Toby)

Comparing his friendships at West-Side to those 'back home,' and in turn highlighting the instrumentality of his football academy friendships, Toby adds:

\footnotetext{
"People here [at home] I could tell, but like at West-Side you dunno who you can trust cos you don't actually know them that well...They're not really part of my life, they're just there for my football bonding not my social bonding or nothing like that, they just help me play football better and all that." (Toby)
}

\section{Negotiating friendships on the outside}

While boys were negotiating the peculiarities of their Academy friendships 'on the inside' of West-Side Academy, they were also sustaining and dealing with changes in existing friendships that had been formed 'on the outside' of the Academy. Echoing Ezzy's ${ }^{64}$ description of how competitive workplace cultures can lead workers to retract from wider social relations outside of the workplace (a minimalisation of the self), boys at West-Side sometimes felt alienated or disconnected from their 'old friends,' as though they were making a strategic choice between two identities. What was particularly striking was how the boys often rationalised their compromised friendships outside of the Academy with (an instrumental, individualistic) discourse that reflected the belief that they were making the necessary 'sacrifices' for a career as a professional footballer. Boys believed the football Academy offered them more, in terms of procurable life satisfactions, than the 'outside world:' perhaps a factor in the demise of some outside social relations. As Toby illustrates below, for some boys there was a 
conflicted sense of commitment to 'career' versus 'friends.'

\begin{abstract}
"You sometimes have to sacrifice your friendships with some people, well not your friendship but friend[sentence trails off]...like if I wasn't at West-Side, then I'd be out with my mates I'd be so much closer to people I hang around with, but you can't go out with them as much...like, you would be training and they'd be going out with other people so like friendship could be...I dunno if they were true friends it wouldn't be that bad but like with some people if they don't get to see you they go off you. But if you're really that important to them your friends and that wouldn't be that bothered, if they knew your football meant everything they wouldn't be that bothered, but then some people worry about that, about losing friends." (Toby)
\end{abstract}

The commitment to being an Academy footballer described by Toby meant that his social engagements were often considered carefully, with social activities requiring a sort of 'risk assessment.' Toby adds that back home his friendship groups have fluctuated somewhat as a result of coming under pressure from some 'friends' to drink (alcohol), smoke (cigarettes), and 'wander around the streets' doing 'stupid things.' 'Them things I said no [sic],' he said, 'I don't wanna do stuff like that. That stuff could jeopardise my career, I wanna do something worthwhile, goin' to football.'

It was also interesting to hear how some boys rationalised their experiences of 'missing out' in relation to interactions with their 'outside' friends. Declining offers and putting up with the 'pressure' from outside friends was typically considered part of the 'deal' when playing for a professional football club. For example, Will believes that his aspiration to be a professional footballer meant that 'missing out,' while difficult, had been something '...you just learn really, and you just gotta get on with it...I'd rather be playing football anyway, just because, I know that I could make a career out of it.' Similarly, when pressed on the notion of 'missing out,' Joel resisted: 
“I wouldn't say it annoys me cos I can't be arsed anyway! I don't think I'm missing out, it's just not something I've done, cos I'm doing stuff that is beneficial, you know, if I'm gonna try at football, don't wanna cut corners, you know." (Joel)

Joel adds that after 'saying no' a few times, his outside friends have come to understand his commitment to being a professional footballer: 'It's just like 'nah, I got football'...they know you're at West-Side so it makes them pressure you less, say like they don't wanna put your future at risk.' Alternatively, Connor suggested that while 'everyone plays football' in his local area some of his friends have not yet grasped the seriousness of his commitment to West-Side Academy. 'They're like, it's all the same...you can still come to the party,' he says. '[They] don't understand that it's a bit more serious and that I could actually get a career out of it.' For these boys (Will, Joel, and Connor) football is 'serious' work: a demanding opportunity to 'make a career.' Highlighting the feelings that emerge from engaging in this demanding career opportunity, Toby notes that:

\footnotetext{
"You think about it all and it blocks up your head...Your mates [at home] don't realise how hard you gotta work there [at West-Side Academy]....They don't know what you gotta do and how hard it can be, the work you gotta put in when you're not there and in your own time...They don't see all that.” (Toby)
}

For Toby, being an Academy player appeared to invoke feelings of distance and alienation (e.g. 'They don’t realise,' 'They don't know,' 'They don't see') from not just other boys inside the Academy, but also boys outside the Academy; that is, other boys at school or in his local area friendship groups. Describing how he copes when issues in his personal or football-life 'blocks up his head,' Toby notes he would 'take a football and walk around the streets, to clear my head, like just around here, in a circle.' Invoking a similar sense of control of his emotions and restriction in his emotional expression with others, Connor says that any issue or problems he is having 
would generally not be shared with any of his mates, even those outside of the Academy. Connor's comments highlight the limited emotional intimacy he maintained with others. 'Talking to people about all your problems is a sign of weakness I suppose,' Connor says, 'you don't wanna see anyone when you're sad, so when things don't go right I normally run it off, do something to blow off steam, literally run it off.' He adds: 'It's not something I do. I just keep quiet, keep it all in, and deal with it myself.'

\section{Understanding boys' friendships at West-Side: some discussion}

Despite competition and uncertainty being pervasive features of professional footballer's lives, ${ }^{65}$ Roderick has previously suggested that friendships do develop among professional footballers, albeit in the form of highly functional and instrumental social relations through which 'transfers' to other clubs can be negotiated and future employment opportunities can be accessed. ${ }^{66}$ Through the interview data (re)presented in this paper, we have explored and pieced-together some of the ways these boys talked about their peers at West-Side Academy as 'friends.' We have highlighted some of the peculiarities and difficulties of boys' developing and maintaining 'deep' friendships in this setting, and the ways boys navigate a competitive 'work-space' while it disturbs their peer-relationships both inside and outside the academy.

The boys' stories we have (re)presented in this paper suggest that competition and uncertainty (part of the fabric of life or 'playing conditions' at West-Side football Academy) were implicated negatively in the process of friendship-building and hindered the capability of these Academy players to develop emotional-proximity (i.e. close friendships) with teammates. Operating primarily from a Foucaldian perspective, others ${ }^{67}$ have discussed elite sports academies and life in professional football as highly 'disciplinary', coercive spaces, where constant supervision, hierarchical observation, 
and surveillance are pervasive and contribute to players' feelings of existing within a panoptic $^{68}$ 'football bubble.' As a result, young men in these contexts feel may feel unceasing anxiety and an inability to relax due to the 'omni-disciplinary' presence of their teammates and coaches ${ }^{69}$ and may suffer a lack of agency or ability to resist behavioural norms and practices that exist inside the Academy among teammates, effectively 'silencing' the formation of 'alternative' relationships and 'ways of being' or negotiating (self)identity. ${ }^{70}$ Re-reading our data, we are concerned that what is being 'silenced' in this Academy setting (through its competitive and hierarchical structure), are opportunities for boys to engage in meaningful and enriching friendships.

Drawing on Ezzy's ${ }^{71}$ work on engineered workplace cultures, we are concerned that the (hypercompetitive, disciplinary, economic) framework of a professional football Academy like West-Side may 'engineer' (or discipline) a culture of “instrumental individualism" among boys which "prevents [them] from attending to anything other than that which contributes to the productivity and profits of the corporation' subsequently undercutting their opportunities to develop deep, intimate friendships. Borrowing from Ezzy, ${ }^{72}$ a focus on ensuring one's own (potentially economically lucrative) success, may 'leave little possibility for anything other than the individual's devotion to the corporation as a means of devotion to themselves.' Reworking Ezzy's ${ }^{73}$ discussion of corporate workplaces and individualism in light of data in this paper, we suggest that football academies may encourage boys to ignore or reduce their concern for their teammates or at the very least do not provide a culture of openness in which intimacy and a concern for others is valued.

Perhaps in response to an institutional culture in which boys' and young men are (i) constantly under surveillance from coaches, teammates and (increasingly) performance analysis technologies ${ }^{74}$ and (ii) in competition with one another, we found 
that boys seemed to develop instrumental friendships and were perhaps 'play[ing] the game of a simulated community. ${ }^{75}$ Competition and uncertainty characterised the West-Side Academy as a 'workplace,' reducing boys' ability to participate in deep, intimate friendships with other boys in this space.

Providing a way of thinking about boys friendships inside a football Academy, Ezzy $^{76}$ writes: 'Modern engineered corporate culture and its associated institutional structures encourage a form of individualistic moral orientation that has minimal, or only simulated, concern for the other.' Perhaps what our data show, therefore, is not the construction of friendships (as boys call them), but simulated or instrumental friendships: with the particular relations of the football Academy 'workplace' leaving little option for boys to go beyond talking football, joking around and having banter. Not to dismiss boys' own agency and role in the (re)production of their friendships inside the Academy, we might also understand boys (simulated) friendships as a dramaturgical performance of friendship and as a form of 'survival practice, ${ }^{, 7}$ such as that deployed by many workers in the workplace 'to protect and secure themselves in a physical, economic and/or symbolic sense within disciplinary regimes.'

Further, Collinson ${ }^{78}$ suggests that 'while subjectivity is crucially shaped by organization, individuals can also become the victims of their own identity-seeking preoccupations.' Identity and self-fulfilment is (sometimes reticently) bound up with dedication to the role: ${ }^{79}$ as Ezzy ${ }^{80}$ notes, 'This is the identity they have chosen to consume.' Interweaving this theorising ${ }^{81}$ with our own data, we see these boys as both active in, and structured into, maintaining a 'safe' emotional distance from one another as part of their preoccupied, obsessive career-focused 'approach' to being an Academy footballer (and becoming a professional footballer): in the process, anchored to particular forms of 'friendships.' 
Moreover, while boys were negotiating the peculiarities of their Academy friendships on the inside of West-Side Academy they were also sustaining and dealing with changes in existing friendships that had been formed on the outside of the Academy. While there was some evidence that these boys were better able to develop closer friendships with boys outside of the Academy (as one Academy player, Alex, noted directly [p.18-19] his friends 'back home' were not as competitive, more normal and not always trying to out-do each other), the interpretation we make is that the boys in this study sometimes felt alienated or disconnected from their 'old friends,' as though they were making a choice between two identities. Of particular interest was how the boys opted to commit to a 'career' and were wedded to a setting in which opportunities to engage in enduring friendships rich in trust, intimacy and emotional-proximity were limited, and often rationalised the compromising of close-friendships outside of the Academy with discourse that reflected the belief that they were making the necessary 'sacrifices' for a career as a professional footballer. Demonstrating the complexity of social experiences in this setting, our analysis did offer glimpses of boys 'getting on' and being friendly ('joking,' 'having a laugh,' and trying to be friends) with other boys in the context of the Academy, and we even recognised among some boys a desire to 'go deeper' into friendship. This was particularly evident in interviews with boys who had been released from the Academy, when talking about friendships with former teammates: friendships which often faded away. However, despite these moments of 'getting-on ${ }^{, 82}$ a key finding was the lack of trust, emotional intimacy and 'deep,' genuinely caring, reciprocal and enduring friendships between boys inside the Academy, even when they described their peers as 'friends."'

\section{Concluding thoughts, limitations and future directions}

Framing our data analysis through Ezzy's ${ }^{83}$ reflections on the influence of competition 
on workplace social and communal relations, this paper offers an insight into the substance of boys' friendships and how they are negotiated inside the competitive 'work-space' of an English professional football academy. Our findings highlight a lack (and loss) of 'real' friendship, disconnection from teammates, and a general lack of trust and sense of inauthenticity in friendships that once felt good to be part of. We have argued that involvement in the competitive setting of West-Side football Academy served to be a significant impediment in adolescent boys' friendship formation. This is a concern, given that, within sport, previous research has recognised that youngsters' peer-friendships in sport-related contexts play a significant role in shaping their broader mental health and wellbeing. ${ }^{84}$

Accordingly, we call for the emergence of a critical consciousness that seeks to carefully interrogate the ways in which psychological, social, and emotional development might be compromised and warped as youth are increasingly seduced into lives as commodifiable resources. However, given the (economic and cultural) weight of football culture in England, we acknowledge that boys (and their parents) will not easily reject the opportunities (and challenges) of participating in a football Academy and potentially becoming a professional footballer. If the choice for boys is between 'friends' and 'football,' our data suggest that boys will pursue their footballing dreams despite the (potential) costs to peer-relationships and 'football friendships' along this life-path. Moreover, we are not so naïve to think that coaches, football clubs and other stakeholders in the industry of professional football will shy away from identifying, recruiting and 'developing' boys into this life-world. In order to sustain their own livelihoods and the perpetuation of this entertainment industry, these stakeholders are in many senses compelled to continue to do so. 
One challenge in this setting, (as we perceive it) is to imagine ways to 'develop' boys along the professional football life-path while also creating (safe) spaces and opportunities for their continued social and emotional development. Such a challenge holds increasing credence in light of number of factors, including but not limited to: (i) the cultural importance and weight of football culture and its impact on boys lives, (ii) the fact that most boys in the Academy system will never obtain a professional contract, (iii) the reality that a high proportion of the young men who do 'make it' will drop out or be released from their professional contracts before their twenty-first birthday, and (iv) recent research ${ }^{85}$ exploring the impact and challenges of retirement for professional footballers (e.g. anxiety, identity disruption, feelings of isolation). From our perspective, therefore, the challenge to the football academies of the future (as well as those engaged in the professional, adult levels of the game), is to approach player development in ways that maximises performance yet also recognises the human-ness of boys and young men, encouraging and supporting them to develop psychologically and emotionally 'buffering' friendships and rich, multi-faceted 'protective' identities.

In bringing this paper to a close, we acknowledge that our data provided merely a hint at the ways in which organisational structure, discourse, and practice in elite sporting environments and work-places might fundamentally alter how social and emotional connections are experienced by boys. There are, of course, limitations to our data: for example, our data are derived from a small sample, not meant as representative of all boys at all football academies, and are also somewhat limited in breadth and depth by the 'organic' research process by which data on friendships was generated. Clearly, there is further work to be done. For example, further research might seek to explore how individual difference and familial factors (e.g. the role and influence of parents) might serve to amplify or buffer some of the issues identified in this study. Research on 
parenting in high performance domains ${ }^{86}$ has identified that parents of young performers can contribute significantly to children's perception that they are 'objects' charged, first and foremost, with producing performances. Accordingly, such parents can show little regard for encouraging or supporting children's social lives because they perceive it to impede the pursuit of performance excellence. Longitudinal studies tracing friendships in academies across age groups and over time would also be enlightening. Furthermore, future studies should explore the extent to which (despite the obstacles and barriers to emotionally intimate friendships identified) individuals and organisations are able to create 'spaces' that sidestep or resist such barriers, protecting and nurturing the formation of emotionally intimate, caring, authentic and enduring connection. Such cases are likely to prove particularly useful in relation to the ways in which individuals and groups are able to take responsibility for protecting and nurturing aspects of human life such as social and communal relations that are under threat in the midst of workplace environments that Ezzy has described as increasingly neoliberal, competitive, and individualistic. ${ }^{87}$

\section{Notes}

1. Ezzy, "A Simulacrum of Workplace Community."

2. An academy is a youth development programme for boys at a professional football (soccer) club

3. Bourke, "The Dream of Being a Professional Soccer Player;" Holt and Mitchell, "Talent Development in English Professional Soccer;" and Relvas et al., "Organizational Structures and Working Practices in Elite European Professional Football Clubs."

4. Stratton et al., Youth Soccer, 201.

5. Roderick, The Work of Professional Football.

6. Ezzy, "A Simulacrum of Workplace Community."

7. Approximate calculations by the authors, based on there being 92 professional football clubs, eight age group teams from Under-9 to Under-16 per academy, and 12-14 boys per age 
group as was the standard practice at West-Side. Moreover, ever greater numbers of boys are becoming embroiled in the 'academy life-world', since traditionally non-professional ('non-league,' 'amateur' or 'semi-professional') clubs are increasingly developing their own 'academy' development programmes.

8. Ezzy, “A Simulacrum of Workplace Community,” 632.

9. Ibid., 636.

10. Ibid.

11. Ibid.

12. Way, "Boys' Friendships During Adolescence."

13. e.g. Adams, Santo, and Bukowski, "The Presence of a Best Friend Buffers Effects of Negative Experiences;” Nangle et al., "Popularity, Friendship Quantity, and Friendship Quality;" Schnall et al., "Social Support and the Perception of Geographical Slant;" and Thompson, O’Neill-Grace, and Cohen, Best Friends, Worst Enemies.

14. e.g. Coie and Cillessen. "Peer Rejection;" Hartup, "Behavioural Manifestations of Children's Friendships," Ladd, "Peer Relationships and Social Competence During Early and Middle Childhood;" Newcombe and Bagwell, "Children's Friendship Relations;" Parker and Asher, "Friendship and Friendship Quality in Middle Childhood;" Parker and Gottman. "Social and Emotional Development in a Relational Context;" Way et al., " It Might Be Nice to Be a Girl...Then You Wouldn't Have to Be Emotionless."”

15. e.g. Carr, "Adolescent-Parent Attachment Characteristics and Quality of Youth Sport

Friendship;" Carr, Attachment in Sport, Exercise and Wellness; Carr, "Relationships and sport and performance;" Weiss and Smith, "Quality of Youth Sport Friendships;” Weiss and Smith, "Friendship Quality in Youth Sport;" Weiss, Smith, and Theeboom, “"That's What Friends Are For;"” and Smith, "Peer Relationships in Physical Activity Contexts."

16. e.g. Carr, "Adolescent-Parent Attachment Characteristics and Quality of Youth Sport Friendship;" Carr, Attachment in Sport, Exercise and Wellness; Carr, "Relationships and sport and performance;" and Carr and Fitzpatrick, "Experiences of Dyadic Sort

Friendships as a Function of Self and Partner Attachment Characteristics."

17. Carr, "Relationships and sport and performance."

18. Zarbatany, Mcdougall, and Hymel, "Gender-Differentiated Experience in the Peer Culture," 64.

19. Patrick et al., "Adolescents' Commitment to Developing talent."

20. Ommundsen, Roberts, Lemyre, and Miller, "Peer Relationships in Adolescent Competitive Soccer."

21. Green, Every Boy's Dream. 
22. e.g. Kelly and Waddington, "Abuse, Intimidation and Violence as Aspects of Managerial Control in Professional Football in Britain and Ireland;" Parker, "Chasing the "Big-Time;" Parker, "Soccer, Servitude and Sub-Cultural Identity;" Roderick, The Work of

Professional Football; Manley, Roderick and Parker, "Disciplinary Mechanisms and the Discourse of Identity;" and Jones and Denison, "Challenge and Relief."

23. Roderick, The Work of Professional Football, 251.

24. Ezzy, "A Simulacrum of Workplace Community."

25. e.g. Roderick, The Work of Professional Football; and Manley, Palmer and Roderick,

"Disciplinary Power, the Oligopticon and Rhizomatic Surveillance in Elite Sports Academies."

26. Ezzy, "A Simulacrum of Workplace Community."

27. Kelly and Waddington, "Abuse, Intimidation and Violence as Aspects of Managerial Control in Professional Football in Britain and Ireland," 151; and Magee, "International labour migration in English league football," 129.

28. Parker, "Chasing the 'Big-Time;" and Parker, "Soccer, Servitude and Sub-Cultural Identity."

29. Adams, Anderson and McCormack, "Establishing and Challenging Masculinity;" Carter, The Football Manager; and Kelly and Waddington, "Abuse, Intimidation and Violence as Aspects of Managerial Control in Professional Football in Britain and Ireland."

30. Jones and Denison, "Challenge and Relief."

31. Roderick, The Work of Professional Football; and Ezzy, "A Simulacrum of Workplace Community."

32. Roderick, “A Very Precarious Profession,” 256.

33. Roderick, "A Very Precarious Profession;” and Roderick, The Work of Professional Football.

34. Manley, Palmer and Roderick, "Disciplinary Power, the Oligopticon and Rhizomatic Surveillance in Elite Sports Academies."

35. Manley, Roderick and Parker, "Disciplinary Mechanisms and the Discourse of Identity."

36. Roderick, "A Very Precarious Profession;” and Roderick, The Work of Professional Football.

37. In England, 92 professional clubs are structured into four leagues: The Premier League; The Championship; League One, and; League Two. However, the organisation of football in England also supports a number of other "professional" clubs further down the "pyramid" structure, in what is known as the "semi-pro" game (that is, they pay their players a weekly wage). Below League Two there is one national semi-pro league (The 
Conference), and then below this the pyramid structure starts to regionalise into North and South, gradually becoming more localised and regional the further down the pyramid one goes.

38. Parker, "'Chasing the "Big-Time."

39. Roderick, The Work of Professional Football, 151.

40. Brown and Potrac, “'You've Not Made the Grade, Son.'

41. Roderick, The Work of Professional Football.

42. Ibid.

43. Richardson, "New Writing Practices in Qualitative Research," 10.

44. Richards and Emslie, "The 'Doctor' of the 'Girl from the University'?"

45. Glaser and Strauss, The Discovery of Grounded Theory; and Charmaz, Constructing Grounded Theory:

46. e.g. Brown and Potrac, “'You've Not Made the Grade, Son;”" and Sparkes, "Illness, Premature Career Termination, and the Loss of Self."

47. Brown and Potrac, "“You've Not Made the Grade, Son;”" and Sparkes, "Illness, Premature Career Termination, and the Loss of Self."

48. Maykut and Morehouse, Beginning Qualitative Research.

49. Potrac and Jones, "Micropolitical Workings in Semi-Professional Football;" and also see Glaser and Strauss, The Discovery of Grounded Theory.

50. Sparkes and Smith, Qualitative Research Methods in Sport, Exercise and Health, 266.

51. Ibid., 182.

52. Cushion and Jones, "A Bourdieusian Analysis of Cultural Reproduction, Socialisation and the 'Hidden Curriculum' in Professional Football."

53. Ezzy, "A Simulacrum of Workplace Community."

54. Guba and Lincoln. Fourth Generation Evaluation, 243.

55. Sparkes and Smith, Qualitative Research Methods in Sport, Exercise and Health.

56. Ibid.

57. Tracy, "Qualitative Quality."

58. Lincoln and Guba, Naturalistic inquiry; and Guba and Lincoln, "Paradigmatic

Controversies, Contradictions, and Emerging Confluences."

59. Roderick, "A Very Precarious Profession."

60. Ibid., 251

61. Ezzy, "A Simulacrum of Workplace Community."

62. Roderick, The Work of Professional Football; and Roderick, "A Very Precarious Profession." 
63. To strengthen the anonymity of individuals, the names of Jack's teammates whom he mentions in the following interview excerpts have been replaced with numbers rather than pseudonyms. This is so connections are not made between participants' pseudonyms used later in this paper. The importance in these quotations, as we see it, is not the particular individuals named, but rather Jack's own feelings about his teammates and the way he was (or not) able to relate to them.

64. Ezzy, "A Simulacrum of Workplace Community."

65. Roderick, The Work of Professional Football; and Jones and Denison, "Challenge and Relief."

66. Roderick, The Work of Professional Football; and Roderick, “A Very Precarious Profession."

67. Roderick, The Work of Professional Football; Jones and Denison, "Challenge and Relief;" and Manley, Roderick and Parker, "Disciplinary Mechanisms and the Discourse of Identity."

68. Foucault, Discipline and Punish.

69. Jones and Denison, "Challenge and Relief."

70. Manley, Roderick and Parker, "Disciplinary Mechanisms and the Discourse of Identity."

71. Ezzy, "A Simulacrum of Workplace Community," 642.

72. Ibid., 647.

73. Ibid.

74. Manley, Palmer and Roderick, "Disciplinary Power, the Oligopticon and Rhizomatic Surveillance in Elite Sports Academies;" and Manley, Roderick and Parker, "Disciplinary Mechanisms and the Discourse of Identity."

75. Ezzy, “A Simulacrum of Workplace Community,” 642.

76. Ibid., 644.

77. Collinson, "Identities and Insecurities," 536.

78. Ibid., 533.

79. Casey, Work, Self and Society after Industrialism.

80. Ezzy, “A Simulacrum of Workplace Community," 641.

81. Collinson, "Identities and Insecurities;" and Ezzy, "A Simulacrum of Workplace Community."

82. Collinson, "Identities and Insecurities."

83. Ezzy, "A Simulacrum of Workplace Community."

84. Carr, "Adolescent-Parent Attachment Characteristics and Quality of Youth Sport Friendship;" Carr, Attachment in Sport, Exercise and Wellness; Carr, "Relationships and 
sport and performance;" Weiss and Smith, "Quality of Youth Sport Friendships;" Weiss and Smith, "Friendship Quality in Youth Sport;" Weiss, Smith, and Theeboom, “"That's What Friends Are For;"” and Smith, "Peer Relationships in Physical Activity Contexts." 85. e.g. Jones and Denison, "Challenge and Relief."

86. e.g. Rapport and Meleen, "Childhood Celebrity, Parental Attachment, and Adult

Adjustment: The Young Performers Study."

87. Ezzy, "A Simulacrum of Workplace Community."

\section{Bibliography}

Adams, R.E., J.B. Santo, and W.M. Bukowski. "The Presence of a Best Friend Buffers Effects of Negative Experiences.” Developmental Psychology 47 (2011): 1786-1791.

Adams, A., E. Anderson, and M. McCormack. "Establishing and Challenging Masculinity: The Influence of Gendered Discourses in Organized Sport." Journal of Language and Social Psychology 29, no. 3 (2010): 278-300.

Bourke, A. "The Dream of Being a Professional Soccer Player: Insights on Career Development Options of Young Irish Players.” Journal of Sport and Social Issues 27, no. 4 (2003): 399-419.

Brown, G., and P. Potrac, P. “'You've Not Made the Grade, Son:' De-Selection and Identity Disruption in Elite Level Youth Football.” Soccer and Society 10, no. 2 (2009): 143159.

Carr, S. "Adolescent-Parent Attachment Characteristics and Quality of Youth Sport Friendship." Psychology of Sport and Exercise 10 (2009): 653-61.

Carr, S. Attachment in Sport, Exercise and Wellness. Abingdon: Routledge, 2012a.

Carr, S. "Relationships and sport and performance." In Handbook of Sport and Performance Psychology, edited by S.M. Murphy, 400-417. New York: Oxford University Press (Oxford Library of Psychology), 2012b.

Carr, S., and N. Fizpatrick. "Experiences of Dyadic Sort Friendships as a Function of Self and Partner Attachment Characteristics." Psychology of Sport and Exercise 12 (2011): 38391.

Carter, N. The Football Manager: A History. London: Routledge, 2006.

Casey, C. Work, Self and Society after Industrialism. London: Routledge, 1995.

Charmaz, K. Constructing Grounded Theory: A Practical Guide Through Qualitative Analysis. London: Sage, 2006.

Coie, I.D., and A.H.N. Cillessen. "Peer Rejection: Origins and Effects on Children's Development." Current Directions 2 (1993): 89-92. 
Collinson, D. L. "Identities and Insecurities: Selves at Work." Organization, 10, no. 3 (2003): 527-547.

Cushion, C.J., and R.L. Jones. "A Bourdieusian Analysis of Cultural Reproduction, Socialisation and the 'Hidden Curriculum' in Professional Football."'Sport, Education and Society 19, no. 3 (2014): 276-298.

Ezzy, D. “A Simulacrum of Workplace Community: Individualism and Engineered Culture.” Sociology 35, no. 3 (2001): 631-650.

Foucault, M. Discipline and Punish: The Birth of a Prison. London: Penguin Books, 1991.

Glaser, B.G., and A.L. Strauss, The Discovery of Grounded Theory: Strategies for Qualitative Research. Chicago: Aldine Publishing Group, 1967.

Green, C. Every Boy's Dream: England's Football Future on the Line. London: A\&C Black Publishers Ltd, 2009.

Guba, E. and Y. Lincoln. Fourth Generation Evaluation. London: Sage, 1989.

Guba, E., and Y. Lincoln. "Paradigmatic Controversies, Contradictions, and Emerging Confluences." In Handbook of Qualitative Research ( $3^{\text {rd }} e d$.), edited by N. Denzin and Y. Lincoln, 191-216. London: Sage, 1994.

Hartup, W.W. "Behavioural Manifestations of Children's Friendships.” In Peer relationships in child development, edited by T.J. Berndt and G.W. Ladd, 46-70. New York: Wiley, 1989.

Holt, N. and T.O. Mitchell. "Talent Development in English Professional Soccer." International journal of sport psychology 37 (2006): 77-98.

Jones, L., and J. Denison. "Challenge and Relief: A Foucauldian Disciplinary Analysis of Retirement from Professional Association Football in the United Kingdom." International Review for the Sociology of Sport (2016): DOI $10.1177 / 1012690215625348$

Kelly, S. and I. Waddington. "Abuse, Intimidation and Violence as Aspects of Managerial Control in Professional Football in Britain and Ireland." International Review for the Sociology of Sport 41 (2006): 147-164.

Ladd, G.W. "Peer Relationships and Social Competence During Early and Middle Childhood." Annual Review of Psychology 50 (1999): 333-59.

Lincoln, Y., and E. Guba. Naturalistic inquiry. Thousand Oaks, CA: Sage, 1985.

Magee, J.D. "International labour migration in English league football." PhD diss., University of Brighton, 1998. 
Manley, A., C. Palmer, C., and M. Roderick. "Disciplinary Power, the Oligopticon and Rhizomatic Surveillance in Elite Sports Academies." Surveillance and Society 10, no. 3-4 (2012): 303-319.

Manley, A., M. Roderick, M., and A. Parker. "Disciplinary Mechanisms and the Discourse of Identity: The Creation of 'Silence' in an Elite Sports Academy." Culture and Organization (2016): DOI 10.1080/14759551.2016.1160092

Maykut, P., and R. Morehouse. Beginning Qualitative Research: A Philosophic and Practical Guide. London: The Falmer Press, 1994.

Nangle, D.W., C.A. Erdley, J.E. Newman, C.A. Mason, and E.M. Carpenter. "Popularity, Friendship Quantity, and Friendship Quality: Interactive Influences of Children's Loneliness and Depression." Journal of Clinical Child and Adolescent Psychology 32 (2003): 546-555.

Newcombe, A.F., and C.L. Bagwell. "Children's Friendship Relations: A Meta-Analytic Review." Psychological Bulletin 117 (1995): 306-47.

Ommundsen, Y., G. Roberts, P. Lemyre, and B.W. Miller. "Peer Relationships in Adolescent Competitive Soccer: Associations to Perceived Motivational Climate, Achievement Goals, and Perfectionism.” Journal of Sports Sciences 23 (2005): 977-89.

Parker, A. "'Chasing the 'Big-Time:' Football Apprenticeships in the 1990s." PhD diss., University of Warwick: Available online at: http://wrap.warwick.ac.uk/36183/1/WRAP_THESIS_Parker_1996.pdf

Parker, A. "Soccer, Servitude and Sub-Cultural Identity: Football Traineeship and Masculine Construction." Soccer and Society 2, no. 1 (2001): 59-80, DOI 10.1080/714004830

Parker, J.G. and S.R. Asher. "Friendship and Friendship Quality in Middle Childhood: Links with Peer Group Acceptance and Feelings of Loneliness and Social Dissatisfaction.” Developmental Psychology 29 (1993): 611-21.

Parker, J.G., and J.M. Gottman. "Social and Emotional Development in a Relational Context: Friendship Interaction from Early Childhood to Adolescence." In Peer Relationships in Child development, edited by T.J. Berndt and G.W. Ladd, 95-131. New York: Wiley, 1989.

Patrick, H., A.M. Ryan, C. Alfeld-Liro, J.A. Fredricks, L.Z. Hruda, and J.S. Eccles. “Adolescents' Commitment to Developing talent: The Role of Peers in Continuing Motivation for Sports and the Arts." Journal of Youth and Adolescence 28, no. 6 (1999): 741-763.

Potrac, P., and R.L Jones. "Micropolitical Workings in Semi-Professional Football.” Sociology of Sport Journal 26 (2009): 557-577. 
Rapport, L.J., and M. Meleen. "Childhood Celebrity, Parental Attachment, and Adult Adjustment: The Young Performers Study." Journal of Personality Assessment 70, no. 3 (1998): 484-505.

Relvas, H., M. Littlewood, M. Nesti, D. Gilbourne, and D. Richardson. "Organizational Structures and Working Practices in Elite European Professional Football Clubs: Understanding the Relationship Between Youth and Professional Domains.” European Sport Management Quarterly 10, no. 2 (2010): 165-187.

Richards, H. and C. Emslie "The 'Doctor' of the 'Girl from the University'? Considering the Influence of Professional Roles on Qualitative Interviewing." Family Practice 17, no. 1 (2000): 71-75.

Richardson, L. "New Writing Practices in Qualitative Research." Sociology of Sport Journal 17, no. 5 (2000): 5-20.

Roderick, M. The Work of Professional Football: A Labour of Love. London: Routledge, 2006.

Roderick, M. “A Very Precarious Profession: Uncertainty in the Working Lives of Professional Footballers." Work, Employment and Society, 20, no. 2 (2006): 245-265.

Schnall, S., K.D. Harber, J.K. Stefanucci, and D.R. Proffitt. "Social Support and the Perception of Geographical Slant.” Journal of Experimental Social Psychology 44 (2008): 12461255.

Smith, S. "Peer Relationships in Physical Activity Contexts: A Road Less Travelled in youth Sport and Exercise Psychology Research." Psychology of Sport and Exercise 4 (2003): $25-39$.

Sparkes, A.C. "Illness, Premature Career Termination, and the Loss of Self: A Biographical Study of an Elite Athlete.” In Sociology of Sport: Theory and Practice, edited by R. Jones and K. Armour. London: Addison Wesley Longman, 2000.

Sparkes, A.C. and B. Smith. Qualitative Research Methods in Sport, Exercise and Health: From Process to Product. London: Routledge, 2014.

Stratton, G., T. Reilly, A.M. Willams, and D. Richardson. Youth Soccer: From Science to Performance. London: Routledge, 2004.

Thompson, M., C. O'Neill-Grace, and L. Cohen. Best Friends, Worst Enemies: Understanding the Social Lives of Children. New York, NY: Ballantine Books, 2002.

Tracy, S. "Qualitative Quality: Eight 'Big Tent' Criteria for Excellent Qualitative Research.” Qualitative Inquiry 16 (2010): 837-851.

Way, N. “Boys' Friendships During Adolescence: Intimacy, Desire, and Loss.” Journal of Research on Adolescence 23, no. 2 (2013): 201-213. 
Way, N., J. Cressen, S. Bodian, J. Preston, J. Nelson, and D. Hughes. "“It Might Be Nice to Be a Girl...Then You Wouldn't Have to Be Emotionless': Boys' Resistance to Norms of Masculinity During Adolescence." Psychology of Men and Masculinities 15, no. 3 (2014): 241-252.

Weiss, M.R. and A.L. Smith. "Quality of Youth Sport Friendships: Measurement Development and Validation.” Journal of Sport \& Exercise Psychology 21 (1999): 145-66.

Weiss, M.R., and A.L. Smith. "Friendship Quality in Youth Sport: Relationship to Age, Gender, and Motivation Variables.” Journal of Sport \& Exercise Psychology 24 (2002): 420-37.

Weiss, M.R., A.L. Smith, and M. Theeboom. “That's What Friends Are For': Children's and Teenagers' Perceptions of Peer Relationships in the Sport Domain.” Journal of Sport \& Exercise Psychology 18 (1996): 347-79.

Zarbatany, L., P. McDougall, and S. Hymel. "Gender-Differentiated Experience in the Peer Culture: Links to Intimacy in Preadolescence.” Social Development 9, no. 1 (2000): 6279. 